\title{
ARQUEOLOGIA DA ARQUITETURA: OLHAR PAREDES, VER VIVÊNCIAS.
}

Raquel Santos

\section{RESUMO}

O presente artigo pretende, acima de tudo, contribuir para a disseminação dos conceitos e metodologias associados à prática da Arqueologia da Arquitetura. Esta disciplina, nos últimos anos, tem sido aplicada cada vez com maior frequência no estudo de edifícios históricos um pouco por toda a Europa, começando já a dar os primeiros passos para lá do "velho continente". É através dela que aplicamos o método arqueológico na análise de estruturas e conjuntos edificados, produzindo dados arqueológicos através dos quais serão criados modelos de interpretação.

Palavras-chave: Arqueologia da Arquitetura, Análise parietal, Estratigrafia vertical

\section{ABSTRACT}

The main aim of this article is to give a contribution relating the concepts and methodologies associated to the practice of Archaeology of Architecture. In the last years this subject has seen an increase, all over Europe, in its use and application to the study of historical buildings and it's starting to give the first steps outside the "old continent". Is by using this discipline that we apply the archaeological methodology when analysing structures and ensembles of buildings, in order to create archaeological data that will allow the creation of interpretation models.

Keywords: Archaeology of Architecture, Paramental analysis, Vertical stratigraphy 
Este artículo pretende, sobre todo, contribuir a la difusión de los conceptos y metodologías asociados a la práctica de la Arqueología de la Arquitectura. Este tema, en los últimos años, se ha aplicado con mayor frecuencia en el estudio de los edificios históricos por toda Europa, ya que comienza a dar sus primeros pasos más allá del "viejo continente". Es a través de ella que aplicamos el método arqueológico en el análisis de las estructuras y conjuntos construidos, produciendo datos arqueológicos a través del cual se crearán modelos de interpretación.

Palabras clave: Arqueología de la Arquitectura, Análisis parietal, Estratigrafía vertical

\section{Introdução}

Nascida no seio da Arqueologia Medieval e da Arqueologia Industrial, a Arqueologia da Arquitetura evoluiu como disciplina autônoma, utilizando uma metodologia arqueológica no estudo de edifícios ou conjuntos edificados. Através da aplicação de um método de análise estratigráfica a construções históricas, torna-se possível observá-las não só do ponto de vista da História, da História de Arte ou mesmo da Arquitetura, mas também de um ponto de vista arqueológico. Com base nos dados recolhidos através da análise parietal, é criado para cada caso específico um modelo evolutivo, tendo por fim último compreender as vivências associadas ao seu processo construtivo.

\section{O CONCEITO}

Poderemos definir a Arqueologia da Arquitetura como a disciplina através da qual se elabora a história de um edifício, analisando a construção de um ponto de vista arqueológico, sob a premissa de que o próprio edifício fará parte da cultura material da comunidade que nele interviu. O edifício, ou conjunto edificado, passará então a ser observado de uma forma mais crítica e mais abrangente, analisando-se não só estilística e arquitetonicamente, mas também estratigraficamente, de forma a registar e analisar todos os momentos da sua existência (MAÑANA BORRAZÁS, et alii, 2002, RAMALHO, 2002, MANNONI e BOATO, 2002). 
Os seus objetivos passam por (1) conhecer a evolução arquitetônica presente num determinado edifício; (2) a configuração e funcionalidade dos seus diversos espaços; (3) as técnicas e materiais empregues em diferentes zonas e diferentes épocas ou até mesmo (4) esclarecer, comprovar ou refutar hipóteses de interpretação fornecidas pelos dados de uma intervenção no subsolo ou por fontes documentais e/ou iconográficas.

Dentre as diferentes análises científicas que se poderão fazer à construção, podemos apontar a leitura estratigráfica de alçados ou análise paramental como sendo a que mais dados poderá fornecer no sentido de elaborar a sequência histórica do edifício. Contudo, outros tipos de análise serão igualmente relevantes na recolha de dados: escavação arqueológica horizontal, análise estilística e arquitetônica, identificação de materiais construtivos, arqueometria, estudos de espacialidade, registo de marcas de canteiro e outras, estudos cromológicos, etc.

Os dados resultantes (estratificação, cronologias relativas e absolutas, cultura material) permitirão traçar a evolução do edifício e, consequentemente, da comunidade nela envolvida, ao mesmo tempo que se produz conhecimento científico e se mantêm as estruturas que lhe deram origem, se não na sua integridade física, pelo menos através do registo delas efetuado (gráfico, fotográfico, topográfico, descritivo...).

\section{A METODOLOGIA}

A Arqueologia da Arquitetura utiliza uma metodologia arqueológica rigorosa, aplicada a construções históricas. Isto quer dizer que a análise efetuada em campo se baseia no método de registo e análise da Arqueologia, adaptado às condicionantes do contexto vertical em estudo, que poderá ser um edifício ou um conjunto edificado; de natureza habitacional, religiosa ou militar; com maior ou menor complexidade estratigráfica; em ruína ou em bom estado de conservação; abandonado ou ainda habitado; analisado no seu todo ou apenas em parte. Analisando o tipo de intervenções que utilizaram o método da arqueologia da arquitetura efetuadas nos últimos anos, verificamos que existe já um maior número de intervenções em contexto habitacional, em edifícios não classificados, atestando a aplicabilidade desta metodologia a contextos diferentes daqueles em que primeiramente surgiu. Efetivamente, numa primeira fase de expansão da disciplina, a quase totalidade 
destes trabalhos incidia sobre monumentos classificados, religiosos ou militares (igrejas, conjuntos monásticos, castelos e fortalezas), de cronologia medieval ou moderna, e em contexto de intervenções de conservação e restauro, situação que se tem vindo progressivamente a alterar, com o surgimento de um maior número de intervenções de ação preventiva ou de minimização de impactos, muitas vezes sobre edifícios não classificados, de cronologias também mais recuadas (romana, por exemplo) e de características bastante diversas (edifícios civis, rurais ou urbanos). Existe contudo uma lacuna que tende a não desaparecer: a aplicação da metodologia da arqueologia da arquitectura a contextos de arqueologia de subsolo, ou seja, às estruturas e/ou vestígios de edifícios que surjam no decurso de uma escavação arqueológica. Persistente é também a tendência para o investimento público ser aplicado em patrimônio classificado, deixando as intervenções em patrimônio não classificado muitas vezes a cargo de particulares e empresas privadas, gerando assim um maior investimento na recuperação e preservação do patrimônio classificado.

Por outro lado, a metodologia e o tipo de estudo a efetuar (do mais simples ao mais complexo) serão também adaptados aos objetivos e às condicionantes específicas de cada intervenção, bem como à constituição da equipe técnica, que deverá ser multidisciplinar (arqueólogo, historiador, historiador de arte, arquiteto, topógrafo, conservador-restaurador, etc.). Em termos de objetivos, poderemos ter fatores como: a remodelação do edifício ou execução de um projeto de conservação e restauro; a sua musealização; ou mesmo a sua salvaguarda perante uma destruição iminente (quer seja devido a um novo projeto de construção quer devido à ação do tempo). Outros dois fatores serão também determinantes: a verba e o prazo disponíveis para a intervenção.

Para a criação do modelo evolutivo do edifício, a Arqueologia da Arquitetura utiliza então vários instrumentos de análise, os quais fornecerão dados de naturezas diversas. Todos eles deverão ser conjugados e analisados posteriormente em conjunto, cruzando-se os dados da sua análise.

O primeiro destes instrumentos será a pesquisa prévia. Servindo-se de fontes históricas, documentais, bibliográficas, arqueológicas, iconográficas ou mesmo etnográficas (escritas, orais, materiais, gráficas ou fotográficas) proporcionará a obtenção de dados que venham a confirmar ou complementar aqueles recolhidos através da intervenção direta sobre o objeto de estudo, podendo fornecer cronologias absolutas (MAÑANA BORRAZÁS, et alii, 2002). 
A análise estratigráfica dos paramentos será uma análise e descrição de cada um dos elementos de uma construção vertical, atribuindo-lhes um número de unidade estratigráfica murária (UEM) e descrevendo-os numa ficha de unidade com descritores próprios. As UEM's poderão ser elementos arquitetônicos como portas, janelas, arcos, etc.; paramentos, com diferentes aparelhos construtivos; revestimentos; estruturas de condenação (emparedamentos); ou mesmo as interfaces (geralmente de destruição), que na Arqueologia da Arquitetura se revestem de grande importância, sendo estas as unidades que determinam os momentos de ação,enquanto os aparelhos e construções constituem momentos de inatividade. Consoante os objetivos da intervenção, esta análise poderá ser mais detalhada ou mais expedita, incidindo sobre a totalidade dos paramentos ou apenas em parte (CABALLERO ZOREDA, 2009; CABALLERO ZOREDA, 1997, MAÑANA BORRAZÁS, et alii, 2002). Contudo, deverá sempre determinar as grandes fases construtivas; registar e numerar as diferentes unidades identificadas nos paramentos; analisar as relações estratigráficas possíveis entre as diferentes etapas presentes no registo e estabelecer diferentes fases ou etapas da história do edifício, materializadas num diagrama de síntese (RAMALHO, 2002).

Os seus dados fornecerão as bases para a criação do diagrama final do edifício, criando cronologias relativas para os diferentes momentos construtivos.

Não obstante, a análise estratigráfica do subsolo é também um importante indicador. Aliás, a Arqueologia da arquitetura e a Arqueologia do subsolo complementamse, devendo, sempre que possível, ser executadas em conjunto (CABALLERO ZOREDA, 2002, FRANCOVICH e BIANCHI, 2002). Tanto mais que o sítio arqueológico é constituído tanto pelas camadas de sedimento que se depositaram no solo e, até, pelas possíveis estruturas que se encontrem soterradas, como pelas construções em cota positiva que possam existir (MAÑANA BORRAZÁS, et alii, 2002). Ambos os métodos permitem obter dados para a datação relativa dos diversos momentos do edifício, que poderão ser confirmadas através de métodos que permitirão obter cronologias absolutas.

Também a arqueometria e os métodos das ciências naturais (utilizando análises geológicas, mineralógicas, fisico-químicas, etc.), bem como as tipologias (elementos decorativos ou construtivos, métodos e técnicas de construção, marcas de canteiro, etc.) serão instrumentos passíveis de revelar dados importantes para o estudo (CABALLERO ZOREDA, 2009; CABALLERO ZOREDA, 1997). 
Estas diferentes áreas de atuação irão sempre basear-se em instrumentos de análise, tais como a documentação gráfica (plantas e alçados), que terá maior ou menor grau de pormenor consoante os objetivos da intervenção e poderá ser efetuada manualmente ou com recurso a instrumentos digitais, onde se irão identificar as diferentes UEM's; o levantamento fotográfico, que deverá abranger todas as realidades presentes na área em estudo, podendo também incluir ortofotografias ou mesmo levantamentos 3D; e o levantamento topográfico georreferenciado.

Por fim, será elaborado um diagrama final do edifício, tal como uma matriz de Harris para as UEM's, com representação de todas as unidades, organizadas diferentes etapas de construção, reconstrução e remodelação do edifício, bem como diferentes fases construtivas de uma mesma etapa, compilando assim todos os dados recolhidos, ordenando e datando as fases e elementose criando a sequência evolutiva do edifício num mesmo diagrama.

Mas o objetivo final de qualquer intervenção arqueológica não serão os dados em si mesmos, mas sim a sua interpretação: (1) cronológica, ordenando as unidades numa sequência temporal; (2) funcional, compreendendo as funções e como estas se foram alterando e transformando progressivamente; e (3) cultural, interpretando os contextos sincrônicos que configuram a estrutura e a sociedade que deu origem ao objeto de estudo (CABALLERO ZOREDA, 2009a). A partir do modelo de evolução obtido para o objeto de estudo, será então possível tecer considerações de caráter geral no que concerne aos seus habitantes, ao meio envolvente, às condições sociais, econômicas, ambientais ou outras, que influenciaram a sua construção, destruição ou transformação.

\section{APLICAÇÃO DA METODOLOGIA E CONDICIONANTES}

Sistematizando a metodologia atrás exposta, foi criado um Diagrama de Atividades, que poderá servir de base de apoio à realização de um plano de trabalhos em Arqueologia da Arquitetura, estipulando o panorama ideal para uma intervenção deste tipo e, ao mesmo tempo, os requisitos mínimos e as adaptações possíveis, consoante as condicionantes específicas de cada sítio. Em qualquer dos casos, em qualquer conjugação de fatores, a 
intervenção deverá obedecer a uma metodologia rigorosa que permita obter o máximo de informação com os meios disponíveis e perseguindo os objetivos iniciais.

Para iniciar um trabalho arqueológico em qualquer tipo de edifício histórico ou conjunto edificado, classificado ou não, qualquer que seja o seu material construtivo ou cronologia, será sempre necessário levarem conta o motivo que ocasiona essa intervenção, a partir do qual se deverão estipular os seus requisitos mínimos. Esta motivação poderá estar relacionada com obras de remodelação ou de conservação e restauro, projetos de adaptação a novos usos, decorrer de uma intervenção arqueológica no subsolo ou de um projeto ou intenção previamente existente de destruição ou demolição de um dado conjunto edificado, ou até mesmo (em casos raros), por puro interesse científico.

As condicionantes comuns a todos os trabalhos desta natureza serão: os prazos e verbas disponíveis e o fato da intervenção incidir sobre a totalidade ou apenas parte do edifício. A intervenção será sempre adaptada aos meios financeiros existentes, que ditam os objetivos, a duração, os meios humanos e técnicos envolvidos, a metodologia, as diferentes abordagens (sondagens no solo, análises físico-químicas, datações absolutas, estudos específicos, etc.) e ainda o grau de aprofundamento necessário para a análise dos dados recolhidos e sua divulgação. Com um prazo curto e uma verba reduzida será necessário adaptar o tipo de estudo e a equipe afetada, se for possível usufruir de um prazo alargado e de elevados meios financeiros, tanto a equipe como o tipo de estudo deverão ser dimensionados em conformidade. Os prazos encontram-se não só dependentes dos meios financeiros como das condicionantes da própria obra, seja ela de que natureza for, verificando-se que, ao contrário do que seria expetável, a Arqueologia quase sempre entra em campo no decurso da obra e raramente antes. Uma grave lacuna que não Ihe permite servir o propósito de informante do futuro projeto. Idealmente, a equipe de Arqueologia deverá entrar em campo o mais atempadamente possível, por forma a desenvolver o seu trabalho com prazos adequados e obter dados relevantes em tempo útil para que possam integrar a informação constante no projeto de restauro, reabilitação ou transformação do edifício.

No que diz respeitoà extensão da intervenção, o fato de esta incidir apenas em parte do edifício ou conjunto edificado irá inviabilizar à partida um estudo exaustivo, uma vez que ele será sempre fracionado em relação à totalidade.

Ao planejar o trabalho arqueológico deverá ser estipulado o tipo de estudo que se pretende efetuar, de acordo com o grau de pormenor exigido, o motivo da intervenção e os \begin{tabular}{l|l|l|l|l|l|l|}
\hline (C) Rev. Arqueologia Pública & Campinas, SP & v.9 & $\mathrm{N}^{\circ} .1(11)$ & p.60-72 & Jan-Jun/2015 & ISSN 2237-8294
\end{tabular} 
meios envolvidos: (1) rastreio, rápido e econômico (no que diz respeito a meios financeiros, humanos e prazos); (2) levantamento, que conta já com alguma precisão em termos de representação do edifício e seus momentos construtivos; (3) estudo aprofundado, que exige meios alargados; (4) ou um estudo exaustivo, que irá incidir sobre todos os aspectos do edifício, nas mais diversas especialidades. Se se tratar de um projeto de restauro, por exemplo, poderá bastar um simples rastreio ou levantamento, caso os meios não permitam efetuar um estudo aprofundado. No entanto, se estiver prevista a demolição total do edifício, só um estudo aprofundado ou mesmo exaustivo poderá responder a todas as questões formuladas e permitir a criação de um modelo interpretativo válido e completo que será no futuro a única fonte de informação acerca do edifício, entretanto desaparecido. Se os meios envolvidos forem reduzidos dificilmente é possível efetuar um estudo aprofundado e se forem alargados é preferível esgotá-los numa metodologia mais exaustiva ao invés de efetuar um simples rastreio.

No que diz respeito à equipe afeta ao trabalho, esta estará intimamente ligada quer aos meios disponíveis, quer ao tipo de estudo estipulado. Se os prazos e as verbas forem reduzidos, a equipe serátambém. Já se os meios forem alargados e se pretender efetuar um estudo exaustivo, a equipa deverá contar com técnicos das mais diversas áreas como a Arqueologia, a História de Arte, a Fotografia, a Topografia, a Engenharia, a Informática, a Conservação e Restauro, etc. Há ainda que considerar que o próprio motivo da intervenção também terá interferência na definição da equipe: no âmbito de um projeto de restauro será sempre necessário contar com Arquitetos e Conservadores-Restauradores; no caso da demolição do edifício, a intervenção arqueológica não irá necessitar do trabalho destes profissionais, nem os seus dados, de uma forma geral serão úteis para o trabalho de Arquitetura a efetuar, eventualmente, na mesma área.

Estipulado o plano de intervenção, os meios humanos afetados e o tipo de estudo a realizar, irão iniciar-se as diversas fases do trabalho arqueológico, sempre presentes qualquer que seja o tipo de estudo ou meios disponíveis.

A pesquisa prévia será a primeira dessas fases e deverá incluir, no mínimo, uma pesquisa bibliográfica sobre o local. A análise bibliográfica poderá, consoante o tipo de estudo e os meios disponíveis, ser completada com uma pesquisa documental, iconográfica, oral ou outra.

No caso do edifício ter condições para se efetuar uma intervenção direta, a fim de possibilitar a observação dos seus paramentos, as sondagens parietais serão o meio mais \begin{tabular}{|l|l|l|l|l|l|l|} 
(C) Rev. Arqueologia Pública & Campinas, SP & v.9 & N$^{\circ} .1(11)$ & p.60-72 & Jan-Jun/2015 & ISSN 2237-8294 \\
\hline
\end{tabular} 
expedito. No entanto, uma picagem integral das paredes permite uma visão de conjunto. Já as sondagens de subsolo vêm acrescentar informação acerca da ocupação e uso do espaço impossível de obter apenas com base na estrutura edificada. A realização de picagens integrais e de sondagens no subsolo, embora desejável, estará sempre condicionada pelos meios disponíveis, pela extensão da equipe, bem como pelo tipo de estudo. Se se pretende efetuar outro tipo de estudo que não o rastreio e o edifício não apresenta as superfícies paramentais visíveis, terá de existir intervenção direta, tão detalhada quanto os meios o permitirem. Se for impossível intervir diretamente (no caso, por exemplo, de o edifício se encontrar habitado), isso também irá influenciar o tipo de estudo a efetuar.

A fase de levantamento é indispensável em qualquer tipo de intervenção, quaisquer que sejam os meios disponíveis. Num simples rastreio poder-se-á efetuar apenas um levantamento fotográfico, pois este será o mínimo essencial para a representação do objeto de estudo. Outro tipo de estudo necessitará de um levantamento mais detalhado, gráfico ou topográfico, levado a cabo por meios manuais ou tecnológicos, conforme o nível de pormenor exigido e os meios financeiros e humanos disponíveis. Os prazos terão influência na escolha do tipo de levantamento a realizar no sentido em que o levantamento gráfico manual será necessariamente mais demorado que um levantamento fotográfico, um levantamento gráfico efetuado com meios tecnológicos ou mesmo uma representação 3D. No entanto, estes meios serão sempre mais dispendiosos, ao mesmo tempo que exigem técnicos especializados, habilitados para os operar e deles extrair os dados adquiridos.

Tal como o levantamento, a análise paramental é também indispensável numa intervenção deste âmbito, uma vez que ela proporciona a maioria dos dados para a compreensão do edifício. Esta leitura será efetuada com base nos meios disponíveis e nas fases anteriores do trabalho. O tipo de estudo a realizar, o seu prazo e verba ditarão uma leitura mais ou menos aprofundada, condicionada pela existência ou não de revestimentos parietais e pela realização ou não de intervenção direta no edifício. Idealmente, deverá ser realizada no local, com a observação direta das estruturas murárias. Não obstante, será possível levar a cabo a análise parietal com base no levantamento gráfico ou fotográfico. De uma forma geral, esta análise irá incluir a individualização de Unidades Estratigráficas Murárias, identificadas no levantamento produzido e descritas em fichas próprias para o efeito. Mas poderá também contar com o agrupamento dessas unidades em fases construtivas, com a identificação dos materiais utilizados e de tipologias de aparelhos murários, ou ainda de outro tipo de elementos tais como as marcas de canteiro. 
Diferentes instrumentos de análise resultarão do trabalho de campo, consoante o tipo de estudo efetuado: o levantamento fotográfico e a leitura paramental, o levantamento gráfico, caso tenha sido efetuado. Possuiremos igualmente diversos indicadores cronológicos: (1) a cronologia relativa, dada pela observação das estruturas e pela pesquisa bibliográfica efetuada; (2) a estratigrafia murária, presente qualquer que seja o tipo de trabalho; (3) a análise tipológica; e (4) as fontes bibliográficas. De acordo com os meios disponíveis e a intervenção de campo efetuada, poderemos ainda contar com: (1) cronologias absolutas, que requerem não só meios financeiros relativamente avultados, como também a recolha prévia de amostras dos materiais passíveis de datação por métodos absolutos; (2) estratigrafia observada no subsolo, no caso de terem sido efetuadas sondagens de subsolo; (3) análise estilística, que irá sobretudo depender das próprias características do edifício estudado, mas também das competências dos profissionais envolvidos; (4) análises físico-químicas que, dependentes dos mesmos fatores que as cronologias absolutas, poderão fornecer informações relevantes acerca da constituição dos materiais utilizados; e (5) outros tipos de fontes, como as iconográficas ou orais, as quais, a existir, deverão ser confrontadas e confirmadas com os dados obtidos diretamente a partir do edifício.

Chegamos assim à compilação dos dados recolhidos através da intervenção com vista à criação de um modelo evolutivo do edifício, o qual será tão detalhado quanto mais forem os instrumentos de análise e indicadores cronológicos a utilizar. O modelo evolutivo simples, criado a partir de dados escassos como aqueles recolhidos num simples rastreio, poderá ser completado com uma análise cronológica alargada, contendo não só as fases construtivas do edifício como também o processo de construção presente em cada uma delas; uma análise funcional, dada pela observação dos espaços internos, de circulação e visibilidade interior, por exemplo; e uma análise sociocultural, mais ou menos abrangente, essencial para atingir aquele que é o objetivo mais lato da Arqueologia: o conhecimento do Homem (BROGIOLO, 2002). A análise sociocultural poderá ser efetuada com base em quaisquer dados recolhidos, mais ou menos abrangentes, daí resultando que, num simples rastreio, com poucos dados objetivos, essa análise irá ter um componente especulativo maior do que aquele que terá ao tomar por base uma maior quantidade de informação fiável, retirada diretamente do edificado, resultante de um estudo aprofundado ou exaustivo.

Quanto mais detalhadas forem as análises efetuadas, mais preciso e completo será o modelo interpretativo final, que nos trará o conhecimento acerca da população que construiu o nosso objeto de análise, que ali habitou ou que dele usufruiu, que ali operou 
modificações e transformações. Será possível, em alguns casos, compreender o seu modo de atuação, as condições socioeconômicas em que viveu, a alteração dos seus hábitos e das suas necessidades, bem como as implicações daquele contexto estrutural na área em que se insere.

O conhecimento profundo do edifício irá igualmente informar os projetos a elaborar, quer sejam de conservação e restauro, de remodelação ou alteração, bem como servir de base a outros estudos específicos dentro ou fora da área da Arqueologia. A criação de modelos interpretativos deverá também trazer soluções concretas para os projetos a elaborar, expor a totalidade da informação proveniente dos dados recolhidos e procurar responder às questões estratigráficas e cronológicas relacionadas com a ocupação do local.

A sistematização da metodologia a empregar numa intervenção de Arqueologia da Arquitetura, das adaptações possíveis, decorrentes de condicionantes específicas e dos contributos daí resultantes para a elaboração de uma análise final, pretende contribuir também para a realização de mais trabalhos com metodologia própria, mais organizados e informados.

\section{REFERÊNCIAS BIBLIOGRÁFICAS}

BROGIOLO, G. P., "L'Archeologia dell'architettura in Italia nell'ultimo quinquennio (19972001)", in Arqueología de la Arquitectura, 1, Vitoria-Gasteiz: Diputació Foral de Álava, Universidad del País Vasco e CSIC, pp. 19-26, 2002.

CABALLERO ZOREDA, L., "Arqueología y arquitectura: Análisis arqueológico e intervención en edificios históricos", in Curso As Actuacións no Patrimonio construido: un diálogo interdisciplinar (1995, Santiago de Compostela), Santiago de Compostela: Xunta de Galicia, pp. 131-158 e 457-469, 1997.

CABALLERO ZOREDA, L., "Sobre límites y posibilidades de la investigación arqueológica de la arquitectura: De la estratigrafía a un modelo histórico", in Arqueología de la 
Arquitectura, 1, Vitoria-Gasteiz: Diputació Foral de Álava, Universidad del País Vasco e CSIC, pp. 83-100, 2002.

CABALLERO ZOREDA, L., "Registo e interpretação do edificado histórico", comunicação proferida em Coimbra a 27 de Novembro de 2009 no âmbito do Plano de formação Dryas'09 "Introdução à Arqueologia do Edificado", 2009.

CABALLERO ZOREDA, L., "Edificio Histórico y Arqueología: un compromisso entre exigencias, responsabilidad y formación", in Arqueología de la Arquitectura, 6, VitoriaGasteiz: Diputació Foral de Álava, Universidad del País Vasco e CSIC, pp. 11-19, 2009a.

FRANCOVICH, R. e BIANCHI, G., "L'archeologia dell'elevato come archeologia", in Arqueología de la Arquitectura, 1, Vitoria-Gasteiz: Universidad del País Vasco e Instituto de Historia/Consejo Superior de Investigaciones Cientificas, pp. 101-111, 2002.

MAÑANA BORRAZÁS, P., BLANCO ROTEA, R. e AYÁN VILA, X., "Arqueotectura I: Bases teórico-metodológicas para una Arqueología de la Arquitectura", in TAPA Traballos de Arqueoloxía e Patrimonio, 25, Santiago de Compostela: Laboratorio de Patrimonio, Paleoambiente e Paisaxe, pp. 11-99, 2002.

MANNONI, T.; BOATO, A., "Archeologia e storia del cantiere di costruzione", in Arqueología de la Arquitectura, 1, Vitoria-Gasteiz: Diputació Foral de Álava, Universidad del País Vasco e CSIC, pp. 39-53, 2002.

RAMALHO, M. D. M., "Arqueologia da Arquitectura: o método arqueológico aplicado ao estudo e intervenção em património arquitectónico", in Estudos/Património, 3, Lisboa: IPPAR, pp. 19-29, 2002. 
ROSKAMS, S., Teoría y Práctica de la Excavación, Barcelona: Crítica Arqueología, 2003. 